\section{SI or Peer Tutoring: Is One Really Better Than the Other?}

\section{Klara Keim \\ Michelle Kiser}

\section{ABOUT THE AUTHORS}

Klara Keim is a senior at Texas Tech University, majoring in microbiology. She recently completed an internship at the National Institute of Standards and Technology (NIST) and is planning on continuing research through graduate studies.

Michelle Kiser, Ed.D., is Senior Director of the Texas Tech University Support Operations for Academic Retention (SOAR).

et's say a fictional college student, Charlie, is taking a difficult course, such as chemistry. Charlie's first test did not go as well as expected, and Charlie needs help with not only the subject material, but also with how to study in general. This student is motivated to get help with chemistry and finds that the school offers free peer tutoring (Topping, 1996) and supplemental instruction (SI) (Arendale, 1994). Which should Charlie choose? I am both a chemistry peer tutor and an SI leader at Texas Tech University, and I face this challenge on a weekly basis because I provide both services for students. Peer tutoring and SI are both vastly different in methodology and uses, which leaves me to question which service is of greatest benefit for Charlie and other students seeking help in chemistry.

The SI program at Texas Tech University offers peer-led review sessions by undergraduate students who have made A's in the class previously and who show strength in the course material. SI sessions are hosted twice a week. The SI leader attends the class alongside enrolled students and then creates a packet of review material. As an SI leader, I have the independence to make my own review packets and supplemental items for the course under the supervision of the SI administrator. This is unique because I get to choose what I think would be the most helpful for students to focus on for test preparatory purposes. Often I focus on the content that will most likely be tested and that also presents the greatest challenge to students, which helps them increase the likelihood of success on their tests.
As for peer tutoring, Texas Tech University offers a wide variety of tutoring options varying in the target students. For example, there is Honors College tutoring for honors students, Resident Housing Association tutoring offered to students living in specific residence halls, and the Marsha Sharp Center tutoring available to student athletes. Personally, I am employed at the Texas Tech University Learning Center, where we provide free open-access tutoring. Students can drop in according to their schedules and needs. The tutoring resources we provide are unique in that we provide tutoring for anyone who is a student at Texas Tech University. A peer tutoring session typically entails the student sitting down individually with their tutor and working to solve homework problems and ask questions about specific topics that they are struggling with.

Supplemental Instruction benefits students at Texas Tech University in many ways. Students can review the material covered throughout the week on a more personalized and peer-to-peer level. Since a student is leading the session, a relaxed environment is generated that is open to discussion and questions (Altomare \& Moreno-Gongora, 2018). Students seek out SI because they did not understand something in the classroom, and they need further explanation. During my sessions, I try to act as a facilitator of material between the professor and student. I strategically organize my packets and re-teach the material to promote student success on exams. The amount of material students cover in a week is immense, and I try to help them sort out exactly what are key elements, what is going to be tested, and how it will be tested.

Peer-tutoring relies on completely different strategies than SI. During peer-tutoring, students typically come in for help because they need oneon-one help with getting through their homework (Clarence, 2016). I provide less test preparation and more homework help when I am tutoring. With SI, students who attend sessions consistently from the beginning of the semester are set up for success because they are taking control of learning the material

\section{In an ideal world, I think that} \section{Sl and tutoring would be} most effective in conjunction with one another. 
from the start. These students typically have a base understanding of the material. Tutoring seems to me more like a catch-up session for students. They express a feeling of being lost, possibly because they are not attending class or SI sessions, so they do not have the base knowledge for solving their homework. My job is to guide them back to understanding. On the other hand, SI can oftentimes lead students to depend heavily on the instructor to help them develop a step-by-step method to solve the problem in addition to receiving the answer. Therefore, to benefit fully from attending $\mathrm{SI}$, students must practice problems independently and utilize the instructor as a means to test their knowledge.

In an ideal world, I think that SI and tutoring would be most effective in conjunction with one another. Students would attend class as scheduled then attend SI for a break-down review of the material that week. I think that then, if they do not understand, they should attend peer tutoring for further clarification of specific concepts. Returning to the original question regarding which is better-SI or peer tutoring-it turns out that you cannot ask which is better because effectiveness depends on the details: the student, how much they have attended class, and the context (e.g. does the student need help with a single assignment or more extensive assistance?).

I have tried to take a balanced view in my discussion, but I must confess that I personally prefer $\mathrm{SI}$. The vibe that I get from $\mathrm{SI}$ is more open, relaxed, and an altogether fun way to learn a really difficult subject. SI gives students a chance to interact and learn in a less formal environment that further motivates them to receive extra help, check their knowledge, and improve their grades (Marrone \& Draganov, 2017). Supplemental Instruction feels more like a preventative measure in that, if students utilize it first, they might not need peer tutoring later on. UItimately, neither option should be considered better nor worse but should be considered in terms of how the student uses it to achieve academic success. In this case, I believe that it would benefit Charlie to utilize both $\mathrm{SI}$ and peer tutoring resources. He could maximize his chances of understanding the material by attending SI sessions regularly to gain a deeper understanding of the material taught in class. Then, as further questions arise while solving homework problems and studying, he should seek more individualized help by meeting with a peer tutor.

\section{References}

Altomare, T. K., \& Moreno-Gongora, A. N. (2018). The role and impact of Supplemental Instruction in accelerated developmental math courses. Journal of College Academic Support Programs, 1(1), 19-24.

Arendale, D. R. (1994). Understanding the Supplemental Instruction model. In D. C. Martin and D. R. Arendale (Eds.), Supplemental Instruction: Increasing student achievement and retention. (New Directions in Teaching and Learning, No. 60, pp. 11-21). San Francisco, CA: Jossey-Bass.

Clarence, S. (2016). Peer tutors as learning and teaching partners: A cumulative approach to building peer tutoring capacity in higher education. Critical Studies in Teaching and Learning, 4(1), 39-54.

Marrone, M., \& Draganov, L. (2017). Peer Assisted Learning: Strategies to increase student attendance and student success in accounting. In L. Wood and Y. Breyer (Eds.), Success in Higher Education (pp. 149-165). Singapore: Springer.

Topping, K. J. (1996). The effectiveness of peer tutoring in further and higher education: A typology and review of the literature. Higher Education, 32(3), 321-345. 